\title{
The Blind Men, the Elephant and the CT Scanner
}

\section{Les aveugles, l'éléphant et le tomodensitomètre}

\author{
by ROBERT G. EVANS \\ Professor of Economics \\ University of British Columbia \\ Vancouver, BC
}

\begin{abstract}
The parable of the blind men and the elephant suggests that disputes among scholars arise not so much from errors of fact and argument as from differences of perspective - incomplete perceptions, each from a different angle of view, of a more complex reality. The CT scanner offers an analogy, taking two-dimensional images from multiple points of view. The heart of the device is the computational process integrating these images into a three-dimensional view consistent with each. Effective interdisciplinary research requires the institutional equivalent of the CT scanner's integrative capacity. The normal dynamics of university-based research, however, pull instead toward disciplinary solitudes. Our new journal is a step in the right direction, but there is still a distance to go.
\end{abstract}




\section{Résumé}

La parabole des aveugles et de l'éléphant laisse entendre que les conflits entre savants sont dus non pas tant aux erreurs de fait et d'argument quaux différences de perspective - des perceptions incomplètes, chacune vue sous un angle différent - d'une réalité plus complexe. Le tomodensitomètre offre une analogie en montrant des images bidimensionnelles sous des angles multiples. Au cœur du dispositif se trouve un processus computationnel qui intègre ces images en une vue tridimensionnelle conforme à chacune. La recherche interdisciplinaire efficace exige l'équivalent institutionnel de la capacité d'intégration du tomodensitomètre. Toutefois, la dynamique normale de la recherche universitaire tend plutôt à créer des solitudes disciplinaires. Notre nouvelle revue constitue un pas dans la bonne direction, mais il reste encore beaucoup de chemin à faire.

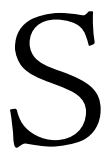

ix blind men of Hindustan, we are told, once went in search of that wonderful creature, the elephant. Or, perhaps there were only three blind men, in Han China. Yet again, there were anywhere between three and eight, somewhere in the Middle East. In the Buddhist original (?) the number is unspecified.

From there, however, the stories are similar. Each man encountered a different aspect of the elephant and drew a different inference as to its essential nature. One walked into its side, concluding that an elephant is like a wall. Another, prodded by the tusk, declared that an elephant is like a spear. The chap hanging onto the tail was convinced that he had found a sort of rope. And so on.

Asked for a description of the elephant, each firmly and confidently gave his opinion, solidly grounded in empirical experience and all radically different. In the Buddha's tale:

Then they began to quarrel, shouting, "Yes, it is!" "No, it is not!" "An elephant is not that!" "Yes, it's like that!" and so on, till they came to blows over the matter.

Brethren, the raja [who in this version had presented the elephant] was delighted with the scene.

Just so are these preachers and scholars holding various views blind and unseeing. ... In their ignorance they are by nature quarrelsome, wrangling and disputatious, each maintaining reality is thus and thus.

Then the Exalted One rendered this meaning by uttering this verse of uplift:

"O how they cling and wrangle, some who claim

For preacher and monk the honoured name! 
For, quarrelling, each to his view they cling.

Such folk see only one side of a thing."

(Udana 68-69)

Rarely does an economist have a chance to offer a verse of uplift. Not to be missed; it may not come again.

Disputes among scholars are not new (nor, indeed, is that observation). But the parable of the elephant suggests that the disagreements are rooted not so much in "errors of fact and argument" as in differences in perspective, in the angle from which the subject matter is approached. If so, then they will not be resolved through further collection of facts or refinement of arguments so long as the contrasting perspectives remain unchanged. What the scholars needed, to grasp (figuratively) the elephant in its full elephant-ness, was some means of integrating and reconciling their (perfectly valid, but radically incomplete) individual observations.

The CT scanner offers a natural analogy. That device records a set of two-dimensional images, each taken from a different point on a circle around the object being scanned. The trick is then to construct, using a complex computational process, a three-dimensional representation of the scanned object that incorporates and is consistent with each of the two-dimensional visual "slices."

Finding a way to synthesize the individual perspectives was the crucial problem that the inventors of the CT scanner solved, and the students of the elephant did not. And it is a matter of explicit procedure or mechanism. Simply laying the various twodimensional images on top of or beside one another would be no more informative than having the blind men expound their conclusions simultaneously or in some particular sequence or pattern. Aggregation is not synthesis.

Healthcare Policy is one response to a widely held conviction among students of healthcare. Comprehending the complex structures and processes that make up a healthcare system requires integrating perspectives from a number of disciplines and backgrounds, in and outside the academy. The journal provides a shared space, a "watering hole," to shift the metaphor yet again, where we can each bring observations and conclusions drawn from our own individual perspectives and present them side by side. But contiguity is not necessarily communication; it is at best an improved opportunity for communication. You can lead a horse to water, but can you make him think?

As it happens, there is quite a bit known about the procedures and processes that promote the integration of differing intellectual perspectives. Both psychology and political science can contribute insights from experiment and experience - as, indeed, can any thoughtful observation of small-group behaviour. The first and most critical step is recognition of mutual interdependence. External threats are particularly effective.

Joe Di Stefano from the University of Western Ontario gives the example of the late Red Adair, the famous leader of a team specializing in putting out oilwell fires. 
While they are sitting on the sand, discussing how best to tackle a particular fire, the team members are, Di Stefano says, textbook models of how to elicit and synthesize differing points of view so as to maximize the value of their collective information. The incentives are strong: if they make a mistake, they all go together to Kingdom Come.

The stakes are not quite so high in health services research - at least, not for the researchers themselves. But the point is the same. Few of us will make the effort to understand another's perspective out of mere intellectual curiosity. Genuine interdisciplinary work requires that a group be, for whatever reason, collectively seized of a task or problem that defeats solution within the conceptual framework of a single discipline. (It probably helps if rewards or penalties are involved.)

If the members of a group can reach the point of recognizing that each possesses only a piece of the puzzle, the next step is to understand that reiteration and elaboration of one's own perspective is generally futile, if not actively counterproductive. Digging in, like the blind men in the tale, goes nowhere. Somehow, one has to learn to see the world from a different perspective, or several. "Why on earth would he think this obvious spear is actually a rope? So, tell me more about the rope. I just don't see it.") This takes time and effort, and a fair amount of mutual respect, goodwill and patience. You have to get inside the other's way of thinking and identify the basic assumptions, typically so basic as to be unspoken. But it can work if all involved want it to - which brings us back to the incentives.

The incentives governing the academic enterprise can be, from this perspective, quite perverse. ${ }^{1}$ The disciplines have evolved powerfully to discourage cross-border communication. (I have heard that the exigencies of day-to-day managerial, clinical or policy responsibilities, what with firefighting and alligators, are also pretty effective for this purpose.)

Why would anyone waste time talking to people in the next department over? Those turkeys can't tell a spear from a rope! The proper focus of research should be on the shape and size of spears, their mechanical properties, their chemical composition. Abstract notions of "elephant-ness," some alleged "emergent properties" arising from the combination of insights from different disciplines, are too fuzzy and illdefined to be worth engaging the time of a serious scholar. They do not fit into the conceptual categories that we are all particularly adept at manipulating, or respond to the research methods in which we are expert and others, typically, are not. We have all spent a lot of time and effort acquiring certain types of specialized intellectual capital; these tools then dictate the way we see the world.

So we do not shout at one another, like the blind men, much less come to blows. (Could they actually have landed many punches?) Instead, we draw apart into separate departments, conferences, journals, with little cross-communication. The results of our studies can be published in prestigious journals like Spear: The Journal of Elephantology, where papers are published only after review by "peers" who share the 
same narrow focus and pointed convictions. Otherwise, they would not be peers. And we cannot relax the standards of peer reviews, the guardians and enforcers of disciplinary conformity. Without them, how can we maintain intellectual rigour, identify excellence and allocate research grants to the right people (people like us)?

What, in this context, might serve as an institutional analogue to the CT scanner, a mechanism for synthesizing competing perspectives on complex realities? As it happens, we have a working example, apparently unique to Canada, in the Canadian Institute for Advanced Research (CIAR). The genesis of the Institute's most recent research program, launched last September (at the same time as Healthcare Policy), illustrates the process.

Economic models of human behaviour typically incorporate jejune and implausible psychological assumptions chosen for computational convenience and justified by intradisciplinary convention. No psychologist would take them seriously for $30 \mathrm{sec}-$ onds. A decade ago, George Akerlof (1995) pointed out that relatively minor changes in the direction of greater realism would yield predictions that were not only richer but also more consistent with sociologists' observations of actual group behaviour.

Akerlof and John Helliwell are now leading a new CIAR Program in Social Interactions, Identity and Well-Being, and are in the process of assembling a team of economists, sociologists and psychologists for a long-term, intensely collaborative enterprise to study the social determinants of individual well-being. (But doesn't happiness just depend upon your net worth? That sounds hard; let's go shopping.) The program's website is very encouraging:

Economists have so far neglected to take into account this considerable body of ... empirical research in other social sciences, especially sociology and psychology ... thereby limiting their analysis of well-being. This narrow focus has probably led to incorrect models of economic behaviour and prescriptive policy.

Amen. A health economist would wish only to expand the list of relevant disciplines and would delete the word "probably"

This writer can hardly claim to be a disinterested observer of the CIAR and its programs. But he can speak from very direct personal experience about their transformative effects. Whatever else they did, the CIAR programs in Population Health and in Human Development changed the way their participants viewed the world. "We have seen the elephant."

The members of the new program may set out to build better economic models; they may find they have produced better economists - and sociologists, and psychologists, and ... Intellectual hybrids, like Kipling's armadillo, are comfortable in a wider range of environments. 
The new program - like previous ones - is an exciting venture full of promise. But it may be some time before we see the standard economics textbooks being rewritten by multidisciplinary teams - if, in fact, we ever do.

The CT scanner was a breakthrough in imaging, where there was and is a strong demand for improved pictures (almost independent of therapeutic benefit). There is no similar demand for synthesis of intellectual perspectives. Disciplinary separation, specialization and exclusivity have deep roots in the academy. As Yale political scientist Ted Marmor says, "Nothing that is regular is stupid." Such behaviour may not lead to the advancement of learning, but it certainly leads to the advancement of the learner, and of the discipline. ${ }^{2}$

Academic careers are made by publications in leading disciplinary journals like Spear and Rope, where methodologies are rigorous, highly technical and difficult for outsiders to understand, rather than in broad-based and widely accessible journals like Elephant. It is only partly a joke that the prestige of a paper is inversely proportional to the number of people who will (or can) read it. When deans of faculties - and I know of more than one - declare unapologetically that "excellence" is defined by, and only by, publications in the leading disciplinary journals (in economics, all American), the message is clear enough to those early in their careers: Stay in the groove!

In this environment, embedding institutional mechanisms to support cross-disciplinary research is a dubious battle, uncertain of long-term success. There is no clear career track for hybrid scholars in single-discipline departments, so that recruitment to a cross-disciplinary enterprise depends upon the random accident of particular individuals, well established in their careers, somehow coming to understand the limitations of a narrow disciplinary perspective and having the intelligence and energy to break new ground.

Akerlof and Helliwell, for example, are both outstanding scholars. But they are also toward the end of their respective careers. They will undoubtedly inspire younger colleagues who will do excellent and highly original work, but where will these hybrids fit in the standard university structure? CIAR programs, while typically long-term relative to other research projects, are nonetheless time-limited.

This is precisely the challenge faced in the field of health services research and policy. Our community has come a very long way in Canada, with the formation of the Canadian Association for Health Services and Policy Research and the launch of this new journal, and those who have done the heavy lifting are to be gratefully congratulated. We are developing the mechanisms for synthesis of perspectives, and the people who can see the elephant as well as the rope. But the challenge remains of developing the institutionally embedded career tracks to keep the whole process going, to ensure a future. We are not there yet. 


\section{NOTES}

1 All generalizations are false. What follows may have more relevance to the social than to the true sciences, and institutional cultures certainly vary. But the general characterization is, I think, reasonably accurate.

2 Other disciplines probably have other terms, but to a habitual economist disciplinary behaviour looks like product differentiation and barriers to entry. These behaviours seem to be as effective competitive strategies in the market for ideas as they are in commodity markets.

Akerlof, G.A. 1995. "Social Distance and Social Decisions." Economics Program Working Paper ECWP-59, Canadian Institute for Advanced Research, Toronto.

\section{The secret of knowing about it first.}

The Longwoods eLetter - ideas, policies, best practices, careers, transitions and learning events. Sign up here: http://longwoods.com/skin 1/eletter.html

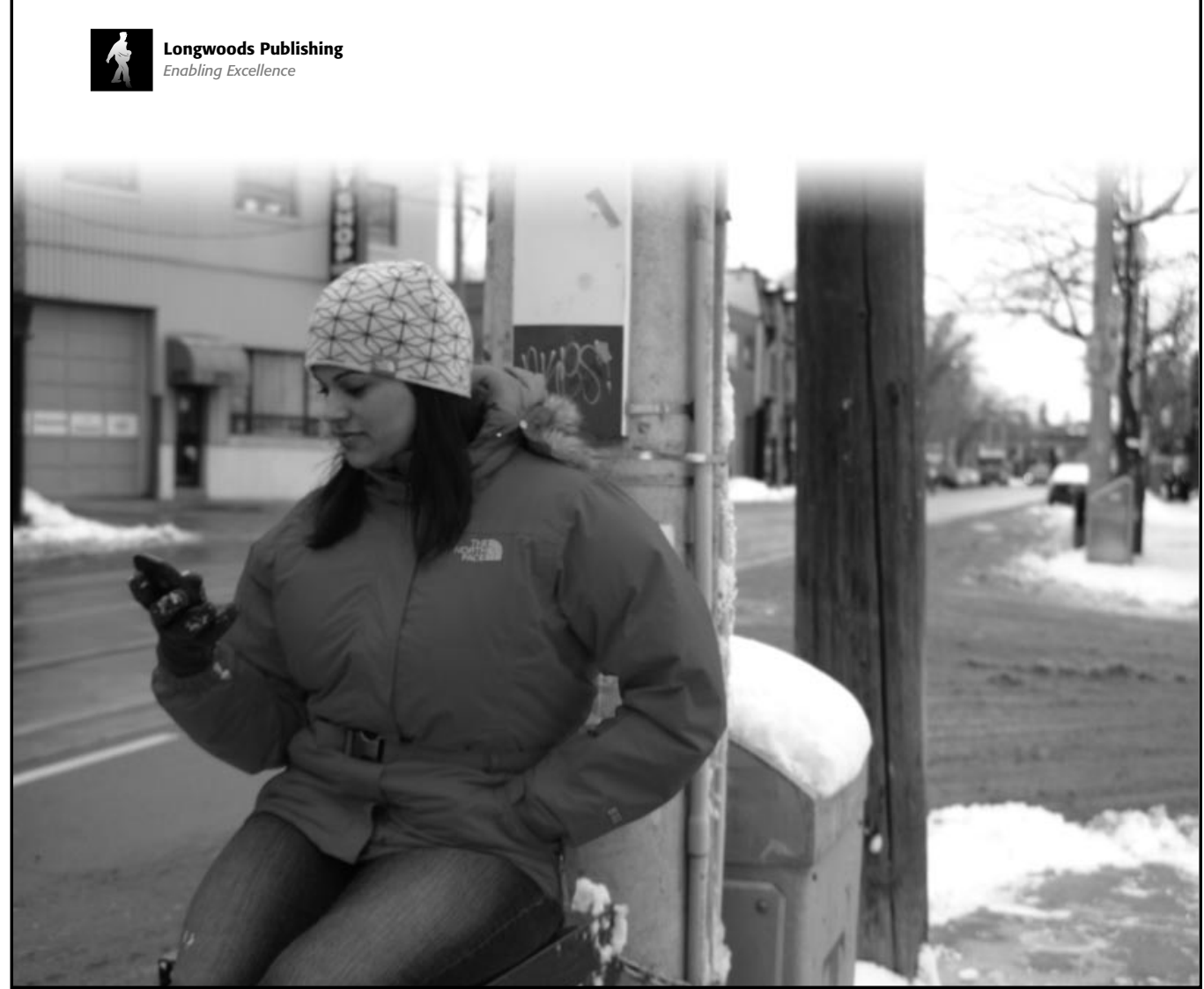

